Synthesis, vol. 24 n 2, e018, diciembre 2017. ISSN 1851-779X

Universidad Nacional de La Plata.

Facultad de Humanidades y Ciencias de la Educación.

Centro de Estudios Helénicos

\title{
Singularidad y despersonalización en los poemas homéricos
}

\author{
Aida Míguez Barciela * \\ * Universidad de Vigo, España
}

Cita sugerida: Miguez Barciela. A. (2018). Singularidad y despersonalización en los poemas homéricos. Synthesis, 24 (2), e018. https://doi.org/10.24215/1851779Xe018 


\title{
Singularidad y despersonalización en los poemas homéricos
}

\author{
Aida Miguez Barciela \\ Universidad de Vigo, España
}

\begin{abstract}
Resumen:
Proponemos una reconsideración de ciertos problemas homéricos prestando especial atención a dos asuntos: la acumulación de riqueza y la pretensión de igualdad en el seno de un colectivo. En primer lugar, se aclara en qué consiste por de pronto la riqueza; en segundo lugar, se considera en qué sentido la empresa de los aqueos es un proyecto común; por último, se expone en qué medida tanto lo uno como lo otro tienden a producir homogeneidad, despersonalización y descualificación, lo cual pone en marcha la pérdida de los límites y, por tanto, de la propia pólis. 1
\end{abstract}

Palabras clave: Riqueza, Economía, Ilíada, Espacio público.

\begin{abstract}
:
The aim of this paper is to reconsider some Homeric problems paying special attention especially to two matters: the accumulation of wealth and the aspiration to equality in the core of a collective project. First, I elucidate the primary sense of 'wealth' in the Homeric poems; second, the common character of the Achaean enterprise is considered; third, I explain how these two problems suggest the loss of limits as a consequence of the homogeneity and disqualification attached to the accumulation of wealth as well as the common political project.
\end{abstract}

KEYwORDS: Wealth, Economy, Iliad, Public space.

El proyecto de los aqueos incluye la práctica de procedimientos que tienden a generar igualación entre sus participantes. Por otro lado, al representante de este proyecto se le critica por acumular riqueza para sí mismo. En este trabajo expondremos en qué sentido estas dos cuestiones resultan coherentes entre sí. Para ello preguntaremos, primero, qué es la riqueza y qué implica que esta se acumule; segundo, en qué sentido el proyecto aqueo muestra en efecto una tendencia a la igualdad.

\section{Relaciones personales y bienes de prestigio}

Tenemos que precisar qué tipo de riqueza aparece en los poemas homéricos. Estamos ante una "economía de prestigio": los bienes no son cosas que se valoren en función de lo que nosotros llamamos su "valor económico", sino en relación con el brillo, el honor y la presencia que confieren (la palabra griega es timé). Un trípode, una armadura o un tejido son bienes de prestigio. Estos no se cambian libremente en una transacción comercial, sino que son donados por personas determinadas en determinadas circunstancias, o bien son ofrecidos como premios en contextos diversos (cf. infra). En la "economía de prestigio" lo que importa es ante todo la creación de relaciones interpersonales, no el provecho ni el beneficio. Se trata de eso que a veces se llama "economía incrustada": las relaciones de intercambio se insertan en el entramado de las relaciones personales; no están abstraídas ni ocurren al margen de una red de vínculos de carácter personal. ${ }^{2}$

Porque el objetivo del intercambio de bienes de prestigio es consolidar y/o mantener una relación personal -de lealtad, obligación y compromiso- entre dos individuos o grupos de individuos, por ejemplo entre un huésped y su anfitrión, es esencial que los intercambios de dones funcionen a largo plazo (no se espera que el contradón se produzca inmediatamente, ni que sea un equivalente exacto; lo que importa es la relación de reciprocidad, y la deuda no hace sino fortalecerla), pues si fuesen instantáneos no se fundaría ninguna amistad o alianza duradera (no habría xenía). 
La relación que se establece mediante un intercambio de regalos no es ni instantánea ni puntual ni impersonal, sino personal, duradera y a largo plazo (en las transacciones puramente comerciales, en cambio, no hay amistad entre las partes, sino neutralidad egoísta: cada uno quiere hacer un buen negocio). Esta relación está además «ritualizada», es decir, el intercambio de regalos tiene lugar según ciertas normas. Así pues, lo que importa en este tipo de intercambio no es solo la obtención de un regalo, sino también la consolidación de un vínculo entre dos partes irreductiblemente singulares: una persona determinada regala a otra un objeto determinado, que, en cierto modo, está impregnado con la identidad del donante (pensemos por ejemplo en el carácter letal de la espada que Áyax recibe en el intercambio con Héctor: $I l$. 7.303-305). Esto comporta singularidad en dos planos: el regalo cambiado -el bien de prestigio- y la identidad de los actores implicados en el intercambio, así como de la propia relación que se establece por esta vía (de compromiso, obligación, amistad, etcétera).

Los bienes no circulan mediante el comercio sino mediante (entre otras prácticas) el intercambio de regalos. En este intercambio las cosas no son bienes cualesquiera intercambiadas por cualesquiera transactores, sino cosas únicas que se regalan personas que han establecido por esa vía una relación personal de dependencia recíproca (en la transacción comercial, cosas alienables se cambian entre individuos recíprocamente independientes). Las relaciones no económicas (la motivación del intercambio de regalos no es nunca básicamente el interés económico) que describe Homero tienen que ver así con la singularidad tanto de las cosas mismas como de los vínculos personales. Los regalos intercambiados en ese tipo de relaciones no económicas son objetos únicos y, en cierto modo, incomparables e inconmensurables: este determinado objeto donado por esta determinada persona; ni el objeto ni el donante son cualesquiera -anónimos e impersonalesni son intercambiables por cualesquiera otros. Esto resulta coherente con otras características de la economía (o más bien no-economía) homérica: ${ }^{3}$ el intercambio interno no es un fenómeno homérico; la actividad comercial no solo es periférica, sino que tiene lugar entre extranjeros o la practican extranjeros; los metales preciosos tales que el oro y la plata son bienes de prestigio, no medios para el intercambio en general; ${ }^{4}$ el ganado, si bien sirve como una medida de valor, no funciona como medio general para el cambio.

En las listas homéricas de cosas valiosas no hay ningún indicio de que estas sean conmensurables en cantidades de una misma magnitud. El oro (dos talentos) que constituye el cuarto premio en la lista de regalos que Aquiles ofrece para la competición de carros en los juegos fúnebres (23.262-270) ${ }^{5}$ no es visto en términos de valor económico sino más bien en términos de prestigio, y lo que importa en un bien de prestigio es la exclusividad y la singularidad, de ahí que pueda valer más a nivel de prestigio un trípode o un caldero de bronce trabajado que unos talentos de oro anónimos sin historia alguna. La historia personal de los objetos - la biografía de las cosas- confiere valor, pero este valor no es económico. En este sentido, la mención de la identidad del donante, que a veces es también el artesano, es una manera de realzar la singularidad y por tanto el valor: cuando Telémaco se dispone a marcharse de nuevo a Ítaca, Helena le regala un vestido hecho por ella misma, un recuerdo de sus manos: $O d .15 .125-129 .{ }^{6}$ Por lo demás, los premios que Aquiles ofrece son singularizados en tanto que el poema se fija en cada caso en su detalle distintivo: el caldero es "bello" y no ha sido tocado por el fuego, la yegua no solo está preñada, sino que es "indómita", etcétera. ${ }^{7}$

Que la actividad comercial no sea central, que se la menosprecie o devalúe (los comerciantes son la antítesis de la heroicidad, cf. Od. 8.159-164), que la unidad económica básica sea la casa (el espacio definido por las relaciones personales), que en lugar del intercambio económico lo que funcione sea sobre todo la donación de regalos que crean vínculos personales, todo esto resulta coherente con las conocidas marcas del "estilo" homérico que habitualmente resumimos refiriéndonos a su carácter naiv: la maestría del épos radica en fijarse una y otra vez en la calidad individual de cada cosa, en no dejar nada sin reconocimiento ni homenaje a su distinción única, en la extrema singularización de cosas, muertos, momentos, acontecimientos. ${ }^{8}$

Hemos visto que el punto de partida homérico no es la conmensurabilidad sino la singularidad de cada cosa. Sin embargo, ya en la Ilíada se critica la riqueza en tanto que tiende a producir emborronamiento de 
la singularidad, lo cual incoa una posibilidad inédita, a saber: la traducción de la diversidad cualitativa de las cosas en cantidades de una misma magnitud. Se trataría de ese viraje que se observa en la semántica de la palabra khrémata, que por de pronto designa las cosas en cuanto contenidos del usar y servirse de, pero, a partir de cierto momento, puede referirse también a las riquezas (con ousía ocurre algo parecido: una palabra de ser y presencia tiende a significar la hacienda, los bienes). Nos ocuparemos de esta crítica en lo que viene a continuación.

\section{Acumulación de riqueza}

Cuando los aqueos quieren movilizar a Aquiles para que luche de nuevo contra los troyanos, envían emisarios que le presentan una lista de las cosas (trípodes, oro, calderos, caballos, mujeres, etcétera) que Agamenón está dispuesto a entregar como indemnización por su injuria en la reunión del canto primero (9.122-156). Dos aspectos son aquí importantes: por un lado, esas cosas de suyo diversas aparecen no cada una por mor de sí misma, sino más bien reunidas en tanto que riqueza para realizar un cierto pago, una indemnización; por otro, Aquiles rechaza la oferta contraponiendo a las cosas mencionadas algo que no se puede adquirir ni amontonar ni sumar en modo alguno: la vida propia. La vida, a diferencia de los bienes, no se puede adquirir una vez perdida; la propia vida es única, inapreciable, irremplazable, inconmensurable; no es una cosa entre otras cosas. A la lista de Agamenón se opone algo que no podría aparecer jamás en una lista de bienes, pues no es un bien propiamente, no es un bien entre otros, sino que es el bien: único, singular, irreductible, inalienable, sin equivalente alguno (cf. 9.401). En relación con esto único no es posible ser más o menos rico, más o menos pobre, por lo que la oferta de Agamenón de hacer rico a Aquiles (no sería pobre...: 125) resulta del todo fútil. (Es interesante reparar en los términos que Aquiles utiliza para referirse a la adquisición de cosas. Aparecen verbos que nombran acciones violentas: la psykhé, a diferencia del ganado, los trípodes o los caballos, no puede ser apresada ni adquirida por pillaje o saqueo, cf. 406-409. Todavía no se trata de comprar ni vender, como tampoco se trata de mercancías; el problema radica en el hecho mismo de la acumulación de cosas, en la que ya se sugiere indistinción y pérdida de la irreductibilidad). ${ }^{9}$

Desde el canto primero Aquiles se ha distanciado de la figura que representa el proyecto colectivo mediante una serie de insultos que insistían, entre otras cosas, en lo que podemos llamar la avaricia de Agamenón. Aquiles decía que, más que ningún otro, Agamenón está "loco por los bienes" (philokteanótate pánton: 1.222), piensa solo en el provecho, la ganancia o la ventaja (kerdaleóphron: 149), y le reprocha que su géras (su parte del botín, su premio de honor) no solo no se corresponde con su mérito individual, sino que siempre es "mayor" que el de los demás (167), así como el hecho de que otros, por ejemplo él mismo, le procuran siempre riqueza (áphenos kai ploûton: 171). Más tarde dirá que Agamenón reparte poco y retiene mucho (9.333). Aquiles critica eso que posteriormente se llamará pleonexía: un deseo ilimitado de acumular riqueza por mor de la riqueza misma, el querer siempre más y más y más. Volveremos sobre el problema del reparto del botín. De momento nos fijaremos en lo siguiente:

Los trípodes, los textiles, el ganado y demás bienes de prestigio no se pueden acumular ilimitadamente, sino que hay un límite natural en su acumulación. Aquiles critica a Agamenón por su deseo ilimitado de riqueza (que en principio tiene un límite), lo cual pone de manifiesto algo inherente al hecho de que las cosas sean tratadas como suma de riquezas: si las cosas no son usadas y tratadas cada una en su condición irreductible, sino como riqueza, es decir, como suma, entonces se borran las diferencias y se pierde el ser único y exclusivo: las cosas vistas como suma son precisamente lo contrario de la singularidad de la cosa. En este sentido, la acumulación o suma de las cosas pone en marcha la pérdida de los límites que los decires griegos asociarán en adelante con la riqueza ("de la riqueza no aparece ningún límite para los hombres": Solón, 13.71). Es decir: la uniformidad y la descualificación derivadas del trato de las cosas como suma generan ilimitación. Para la riqueza en este sentido no hay un límite natural. La riqueza en este sentido es la gran niveladora, la gran emborronadora de las diferencias, la promotora de la indiscriminación y la neutralización. Pluto es ciego en Aristófanes. Tratadas como riqueza, todas las cosas son iguales, están en el mismo plano y son equiparables entre sí. (Esto podrá parecernos trivial, pues la expresabilidad general de las cosas en una substancia común 
es para nosotros el presupuesto obvio.) Esta tendencia se hará evidente ahí cuando la riqueza ya no sea, como en Homero, el objeto valioso, el textil, el trípode o el ganado, sino cierta cantidad de plata, o bien cierta pieza de plata acuñada; en la riqueza en este sentido ya es más clara la tendencia a la ilimitación, pues, si se trata de cantidades, siempre podemos acumular más cantidad de plata. Cuando se las suma o acumula, las cosas pierden su carácter irreductible, es decir, se homogenizan; la homogeneización suprime los límites, produce ilimitación.

Esto es lo que se sugiere en la crítica Aquiles, y esto es lo que, según decíamos, forma figura con el segundo aspecto de la misma, a saber, la tendencia a la igualación en el seno de un proyecto común. Se trata, de nuevo, de denunciar una incipiente abolición de las diferencias o una irrelevancia general. Frente a la nivelación, lo que Aquiles reclama es justamente irreductibilidad, singularidad, diferencia, criterio, límite.

\section{Repartos comunes}

Además del intercambio de bienes de prestigio, en los poemas homéricos se practican repartos comunitarios, por ejemplo, el reparto de carne en un banquete. La distribución en el banquete es "igual" en el sentido de que todos reciben igualmente parte, nadie queda excluido, si bien esta parte no tiene que ser ella misma igual. La distribución implica no igualdad, sino igualación; es la participación misma en el banquete lo que iguala en cierto modo a sus participantes. El mismo problema aparece en la distribución del botín: el botín lo forman bienes comunes, y se supone que todos tienen derecho sobre ellos, sea para recibir cada uno una parte, sea para garantizar la legitimidad del reparto entre los guerreros más sobresalientes. Hay cierto contraste entre la donación de regalos entre particulares y el reparto en el seno de un colectivo. En el intercambio de regalos, un individuo concreto le da algo concreto a otro individuo concreto. La transacción está completamente singularizada. Por la contra, en el reparto de carne en un banquete, o de un botín común, el grupo es la instancia de la que depende el reparto, aun cuando un líder pueda actuar de facto como distribuidor. Los comensales reciben una parte tanto por su calidad individual como por el hecho de formar parte de un mismo colectivo. ${ }^{10}$ La comunidad resulta ser así la instancia que da igual reconocimiento (no reconocimiento igual) a cada uno. La consecuencia de ello es que la particularidad se transciende en este espacio de igualdad que es, por un lado, el reparto de un botín común, y, por otro, el banquete comunitario, el cual, en tanto que todos reciben una parte, activa la tendencia igualadora. ${ }^{11}$ El segundo aspecto de la crítica de Aquiles tiene que ver con esto.

Es sabido que en la Ilíada hay un proyecto común: a raíz de un problema doméstico, pero transcendiendo los límites de lo doméstico, distintos grupos procedentes de regiones distintas y con solidaridades particulares distintas se unen en torno a un mismo objetivo. Este proyecto es inter- o supracomunitario (empresa "panaquea" o "panhelena”), va más allá de las comunidades de origen; implica, por tanto, una cohesión o una solidaridad de segundo orden, la cual no funciona antes de la fuga de Helena, Troya, etcétera, sino que se forma precisamente a causa de esa fuga, y se supone que se disolverá en cuanto el proyecto se cumpla. Puesto que todos esos diversos grupos particulares se han coligado para hacer frente a un otro común, un plano de relaciones nuevas, que transciende las relaciones particulares, queda constituido (el ejército de Agamenón pretende actuar como un único grupo, a diferencia de lo que ocurre en el bando contrario: exterioridad de los aliados en relación con Héctor y su entorno).

La distancia de Aquiles se comprende contra este telón de fondo: uno de esos grupos particulares se retira del proyecto común, y porque su líder no es una figura cualquiera, sino que es Aquiles, el proyecto se resiente en seguida, las cosas no siguen su curso, todo se tambalea. Desde esa separación Aquiles formula su crítica, reivindicando a la vez algo que ahí se está borrando o perdiendo (quizá sea el propio Aquiles el que ahí y de esa manera se pierde o acaba perdiéndose). Aquiles menciona qué es lo que se está perdiendo; en el proyecto común no tiene lugar kháris (9.316). La kháris es la singularidad de lo singular y la irreductibilidad de lo irreductible; pero, a la vez, es el favor y el contrafavor, el agradecimiento por un servicio prestado, la observancia de la reciprocidad en un sentido muy concreto (por ejemplo, en la donación de regalos, al recibir un regalo, el huésped contrae una obligación de reciprocidad con el donante que se traduce en servicios 
concretos). Aquiles critica la pérdida del brillo singular en un proyecto cuyas prácticas internas implican una tendencia a la igualdad. Según Aquiles, en el reparto de los bienes comunes no se reconoce la distinción individual, sino que "hay una misma recompensa tanto para el que se esfuerza mucho combatiendo como para el que no se esfuerza nada, un mismo reconocimiento tanto para el bueno como para el malo" (318-320). Porque no se recompensa debidamente el mérito singular, sino que se da igual reconocimiento tanto a unos como a otros, la kháris se pierde, el ser de cada uno empalidece.

Aquiles denuncia que en el seno de ese colectivo formado ad hoc para tomar Troya se pasen por alto las irreductibles diferencias, lo cual tiene una evidente conexión con el hecho de que el proyecto uniformice en cierta medida las diferencias entre las comunidades de origen, la pertenencia a una tierra y una casa concreta, etcétera. Esto es lo que Aquiles (él mismo una figura de belleza y mérito incomparable) critica en su gran discurso de rechazo a la embajada: la irrelevancia de la distinción individual, lo cual -ahora lo vemos- es coherente con su crítica a Agamenón en tanto que figura que acumula riqueza, acumulación que sugiere pérdida de las diferencias cualitativas (irrelevancia de las cosas al ser vistas o tratadas como suma).

Esta tensión se percibe también en el comentario cómico que el narrador de la Ilíada hace a propósito del encuentro de Glauco y Diomedes. En reconocimiento de sus vínculos privados, Glauco cambia su armadura de oro por la armadura de bronce de Diomedes. Entonces aparece un comentario que pone la práctica del intercambio de regalos bajo una ambigua luz (6.234-236). Se dice que, haciendo lo que hizo, Glauco no estaba en sus cabales, cometió una estupidez, lo cual implica ver el intercambio amistoso bajo una luz que podríamos llamar proto-económica: los vínculos de amistad son antieconómicos (Glauco hace un mal negocio) solo si el intercambio de regalos es visto no como reiteración de la amistad heredada, sino como intercambio de cosas que tienen un valor en sí mismas (y esto en relación con una medida de valor que no es todavía el oro ni la plata, sino que son bueyes: armadura por valor de cien bueyes se cambia por otra cuyo valor son nueve bueyes), ${ }^{12}$ y lo tienen al margen de toda relación personal.

Comentar que Glauco ha hecho un mal negocio al reforzar por esa vía sus vínculos privados con Diomedes implica dos cosas en cierta manera contradictorias: por un lado, el encuentro expresa la todavía primacía de las relaciones personales sobre las públicas (acuerdan evitarse el uno al otro como los enemigos que son en el contexto de la guerra de Troya); por otro, la distancia épica (la misma que tiende a ignorar elementos contemporáneos como la construcción de templos o las instituciones de la pólis emergente) problematiza esta primacía, pues el intercambio de las armaduras se interpreta no solo desde el punto de vista de las relaciones personales "subjetivas", sino también del intercambio de cosas "objetivo", intercambio en el que lo que cuenta es el valor "económico" de la cosa, no su relevancia personal.

\section{Juegos, lamentos y venganzas}

Hemos visto la tendencia a la despersonalización (a partir de una situación en la que la personalización es el presupuesto) en relación con los repartos comunes, así como con la acumulación de riqueza. En ambos casos observábamos la tendencia a la uniformización interna inherente tanto al proyecto de igualdad como al hecho de que la riqueza se busque por sí misma y se acumule. No en vano en la historia de la pólis la agoré es tanto el espacio en el que se reconoce algo que es lo mismo para todos (escritura y publicidad de las leyes) como el lugar en el que se intercambian cosas (no regalos, pero tampoco mercancías), lo cual, teniendo en cuenta que el intercambio produce igualación tanto de las cosas como de los transactores, genera homogeneidad interna, y, con ella, la disolución de la propia pólis.

Esta ambigüedad entre singularidad y despersonalización aparece en los poemas homéricos también por lo que se refiere a otros asuntos: 1) las reglas de los juegos, 2) la práctica de lamentos fúnebres, y 3) la resolución de conflictos intracomunitarios. ${ }^{13}$ Terminaremos este trabajo delineando una dirección para su tratamiento.

1) En los juegos competitivos, el mérito personal se despliega públicamente. Ahora bien, lo que ocurre en la primera de las competiciones de los juegos celebrados en honor de Patroclo sugiere que el mérito individual de algo o de alguien podría no reconocerse debidamente, y esto por mor de la participación misma en el juego público, cuyas reglas se suponen conocidas y vinculantes para todos. Los caballos de Menelao son de suyo 
mejores que los de Antíloco; sin embargo, este logra que sus caballos, de suyo peores, sobrepasen a los otros, de manera que, aunque Menelao se queje argumentando que sus caballos son sin duda más veloces (nadie se lo niega), el hecho de que Antíloco haya sabido hacer, por los medios que sea, que sus caballos quedasen por encima de los otros se impone a pesar de todo. En ciertos contextos y momentos, las reglas del juego pueden hacer que el valor intrínseco de algo se relativice.

2) Que los lamentos fúnebres son de entrada un problema personal se nota en su asociación con las mujeres, las cuales, en tanto que figuras de la casa, ${ }^{14}$ resumen el problema de las relaciones de parentesco, relaciones en las que no hay despersonalización sino lo contrario: en la casa cada uno es exactamente la persona que es, está en la relación que está, de manera no-intercambiable, con las demás personas. Las mujeres son en los poemas homéricos, no de manera exclusiva, pero sí predominante, las que profieren lamentos precisamente porque en el lamento se trata de evocar las cualidades irreductibles del pariente único. Este tipo de lamento atraviesa toda la Ilíada y adquiere mayor relevancia hacia su final. Ahora bien, los lamentos fúnebres constituyen un problema no personal sino "privado" solo desde el punto de vista de un espacio "público". De ahí que en Troya, donde no está claro que se haya constituido un espacio de este tipo, tal como no hay entre los troyanos ninguna pretensión de constituir un proyecto supra o intercomunitario, no haya todavía necesidad de confinar los lamentos personales a un espacio privado, y por eso las mujeres lloran a Héctor ante todo el dêmos de Troya $(24.712,776)$. Será la constitución de un espacio público lo que transforme estos lamentos personales en un asunto privado, por eso la pólis (la comunidad que ha abierto en sí misma un espacio vacío y para todos) acabará restringiendo la presencia de estos lamentos femeninos. Cuando ya esté clara la constitución de un espacio público, entonces sí habrá necesidad de circunscribir con claridad qué va en cada sitio y quién hace cada cosa.

3) En Homero aparecen asesinos que tienen que exiliarse para evitar la venganza de los parientes del asesinado. Esto quiere decir que, por de pronto, el homicidio se sitúa en el plano de las relaciones personales (una ofensa personal se repara personalmente). Ahora bien, frente a la venganza personal está la compensación pública (lo cual podría evitar el exilio). Un procedimiento público instituido para resolver conflictos de violencia intracomunitaria aparece en la écfrasis del escudo de Aquiles de la Ilíada (18.497-508).

Se trata de una disputa por un asesinato. Ahora bien, en la escena no están pariente contra pariente, sino que hay un grupo de hombres cualificados que se han reunido formando un círculo; también está presente el dêmos: el colectivo, la multitud, toda la gente. El problema personal se ha emplazado en un espacio público, se ha llevado al centro de la comunidad. El asesinato no es ya un mero asunto entre particulares, sino que se ha puesto en manos del colectivo. Las partes hostiles se someten a una instancia superior que, en principio, aspira a la impersonalidad (hay también un árbitro en la reunión: un histor), y, en relación con esta instancia, las dos partes son iguales (vemos de nuevo igualación en el seno de una agoré).

La reunión de la gente implica la pretensión de encontrar un procedimiento que oblitere la venganza entre parientes. En lugar de responder a muerte con muerte, se pretende negociar la aceptación de una compensación por la parte injuriada. ¿Qué quiere decir esto? En la venganza entre particulares, la muerte singular se cobra como precio otra muerte singular. Un muerto por un muerto. Un ser único por un ser único. En el pago de una compensación, en cambio, la singularidad del muerto se nivela en cierta medida, pues se trata de encontrar una equivalencia a la pérdida, con la consecuencia de que, si bien la solución mediante equivalencia tiene de entrada un alcance solo particular (en este asesinato, esta equivalencia), el hecho mismo del procedimiento público sugiere la posibilidad de que la tasación fijada para el caso singular pueda convertirse en regla general, con lo cual el asesinato tenderá a verse como un caso similar a otros casos, sin consideración de quiénes son particularmente las partes afectadas (tanto litigantes como jueces). Tanto en la aplicación de una sentencia consensuada en público - el caso no lo dirimen las familias, sino la comunidadcomo en la compensación material - no una persona concreta, sino cierta cantidad de algo, no sabemos qué- se observa pues tendencia a la igualación y la despersonalización. Esta tendencia se hará evidente en la tipificación de penas precisas para determinadas ofensas en las leyes atribuidas a Solón: el mismo tipo de 
ofensa recibirá siempre el mismo tipo de penalización con independencia de quién sean la víctima y el ofensor (esta despersonalización se corresponde con la división del cuerpo político en función de criterios de riqueza en lugar de descendencia), lo cual tiene que ver asimismo con la escritura de sentencias judiciales: cuando las sentencias judiciales empiecen a escribirse y publicarse, se aplicarán con mayor facilidad las mismas sentencias en casos similares. La sentencia deja así de ser una solución ad hoc (los mismos jueces podrían juzgar de manera distinta casos similares) y se hace regla, ley válida para todos en una pluralidad de casos.

Un proyecto de castigo según la ley aparece en el planteamiento de la Odisea: el discurso de Zeus en el consejo de dioses contiene algo así como la definición de en qué circunstancias un asesinato no será una mera venganza, sino más bien una sanción legal (o algo próximo a esto). Se trata de explicar en qué sentido lo que ha hecho Orestes con Egisto está justificado.

En primer lugar, el crimen se cometió con conocimiento de causa, pues se realizaron las advertencias pertinentes (Hermes avisa de las consecuencias previstas para las dos acciones tipificadas como delitos, lo cual asegura tanto la intencionalidad como la imputabilidad del crimen); sin embargo, Egisto persistió en su adulterio y cometió asesinato, de manera que el castigo sufrido a manos de Orestes está justificado: no es una venganza, es un ajusticiamiento. Esto se confirma en las palabras ulteriores de Atena: "Así pereciese cualquier otro que tales cosas hiciese" (1.47), lo cual sugiere la posibilidad de aplicación impersonal del procedimiento presentado para casos similares (las primeras fijaciones de leyes contienen fórmulas condicionales expresadas en forma impersonal). Porque la matanza de los pretendientes satisface estas condiciones establecidas de antemano (crímenes tipificados, advertencias, intencionalidad, demostración de culpabilidad, acusación formal previa a la ejecución del castigo), es decir, porque se trata no tanto de vengarse como de aplicar una cierta "legislación", los familiares que al final de poema buscan vengar unilateralmente - de manera privadalas muertes de sus hijos son detenidos y su pretensión es deslegitimada, si bien no está claro que Odiseo pueda librarse de un nuevo exilio o nuevo viaje, por más que el significado de este viaje transcienda con mucho el problema de evitar una venganza. ${ }^{15}$

\section{RefERENCiAS}

Allen, T. W. 1908/1917-1918: Homeri Opera, Tom. III et IV, Oxford.

Austin, M. \& Vidal-Naquet, P. (1986) Economia y sociedad en la Antigua Grecia, Barcelona.

Brown, A. (1998) "Homeric Talents and the Ethics of Exchange", JHS 118: 165-172.

Crielaard, J. P. (2003) “The Cultural Biography of Material Goods in Homer’s Epics”, Gaia 7: 49-62.

Dalton, G. (1974) “Teoría económica y sociedad primitiva”, en Godelier, M. (ed.) Antropología y economía, Barcelona: 179-207.

Donlan, W. (1997) "Homeric Economy", en I. Morris \& B. Powell (eds.) A New Companion to Homer, Leiden: 649-667.

Gagarin, M. (1986) Early Greek Law, Berkeley.

Grierson, P. (1978) “The Origins of Money”, Research in Economic Anthropology 1: 1-35.

Kopytoff, I. (1986) “The Cultural Biography of Things”, en A. Appadorai (ed.) The Social Life of Things. Commodities in cultural perspective, Cambridge: 64-91.

Martínez Marzoa, F. (2009) La cosa y el relato. A propósito de Tucídides, Madrid.

Meikle, S. (1996) “Aristotle on Business”, CQ 46.1: 138-151.

Míguez Barciela, A. (2014) La visión de la Odisea, Madrid.

Míguez Barciela, A. (2016) Mortal y fúnebre. Leer la Ilíada, Madrid

Míguez Barciela, A. (2017) “Los pechos de Hécuba”, en Reboreda Morillo, S. (ed.) Visiones sobre la lactancia en la antigüedad: permanencias, cambios y ruptu-ras. Dialogues d'Historie Ancienne, Suplemento (en prensa)

Monro, D. B. \& Allen, T. W. 1902/1920: Homeri Opera, Tom. I et II, Oxford. 
Morris, I. (1986) "Gift and Commodity in Archaic Greece", Man 21.1: 1-17.

Parry, J. \& Bloch, M. (1989) Money and the Morality of Exchange, Cambridge.

Polanyi, K. (2016) La gran transformación. Crítica del liberalismo económico, Barcelona.

Ross, S. A. (2005) “Barbarophonos: Language and Panhellenism in the Iliad”, CPh 100.4: 299-316.

Seaford, R. (2000) “Aristotelian Economics and Athenian Tragedy”, New Literary History 31.2: 269-276.

Seaford, R. (2004) Money and the Early Greek Mind. Homer, Philosophy, Tragedy, Cambridge.

Ulf, C. (2004) "Ilias 23: Die Bestattung des Patroklos und das Sportfest der 'Patroklos-Spiele' - Zwei Teile einer mirror-story", en H. Heftner \& Tomaschitz, K. (eds.) Ad Fontes! Festschrift für Gerhard Dobesch zum fünfundsechzigsten Geburtstag, Wien: 73-86.

Van Wees, H. (1994) "The Homeric Way of War: The 'Iliad' and the Hoplite Phalanx (I)", Greece \& Rome 41.1: 1-18.

Van Wees, H. (1994) “The Homeric Way of War: The 'Iliad' and the Hoplite Phalanx (II)", Greece \& Rome 41.2: 131-155.

\section{Notas}

1 Este artículo se basa en una conferencia pronunciada en el curso Privado, público, común: tres categorias socioeconómicas para entender nuestra época, UNED, Córdoba, 15-17 febrero 2017.

2 Esto frente a la autonomía de la esfera económica (su carácter "desincrustado") en el ámbito moderno.

3 El concepto de economía suele usarse de la misma manera universal y vacía que ciencia, literatura, religión, etcétera, de tal modo que habría una economía del imperio romano, otra de la Inglaterra del siglo XIX y otra de los indios navajo. "Economía”, en el sentido de "economía de mercado", que es el nuestro por defecto, no es, naturalmente, una categoría universalmente aplicable.

4 Cuando aparecen como medio para realizar un pago, se trata casi siempre de operaciones dudosas.

5 Cito por la edición de Monro \& Allen (1902/1920).

6 Cito por la edición de Allen (1908/1917-1918).

7 Es más, la historia de algunos de los premios es tal que resume en cierto modo los acontecimientos principales de la guerra, no solo los referidos al episodio que relata la Ilíada.

8 Cf. Míguez Barciela (2016).

9 No es que Aquiles desprecie la riqueza, como tampoco desprecia la vida aun cuando la ponga siempre en juego en el campo de batalla. Lo que dice es más bien que no necesita esa riqueza, ni necesita más riqueza, pues tiene suficiente con los bienes que configuran su casa, a los que sumará lo adquirido como su botín personal durante la guerra de Troya (9.364-367). En cualquier caso, la relación que Aquiles tiene con las riquezas en la Ilíada es fundamentalmente una relación de desprendimiento. Así lo vemos tanto en los juegos para Patroclo, en los que pone su riqueza a disposición del colectivo, como en las riquezas que destruye en la pira funeraria (23.166-176).

10 La contribución especialmente meritoria de alguien se reconoce asignándole un trozo de carne especial.

11 En la vida de la pólis, los banquetes comunes son un mecanismo de cohesión interna; la participación en el banquete comunitario encarna la participación en la pólis.

12 El ganado funciona como medida de valor, pero no como medio para el intercambio. Laertes adquiere a Euriclea proporcionando cosas por valor de veinte bueyes, pero no da los bueyes para la adquisición (Od. 1.430-431). Cuando los aqueos quieren obtener vino, ofrecen a cambio no cantidades de la misma cosa, sino una pluralidad de cosas distintas (Il. 7.467-475). Por lo que se refiere a la moneda, la historiografía coincide en señalar que los primeros usos de moneda acuñada (unidades de plata marcada de aproximadamente el mismo peso y tamaño) no tuvieron en origen un carácter comercial, sino más bien político-administrativo (por ejemplo, para realizar un pago uniforme a mercenarios). Por otra parte, las monedas acuñadas por diversas póleis no eran "dinero" en el sentido preciso (moderno) de la palabra: tenían valor intrínseco como metal precioso y no eran el medio exclusivo y general para el intercambio. Donde no hay una única medida de equivalencia general, lo que hay son distintas esferas de intercambio: objetos de una esfera no se cambian por objetos de otra esfera.

13 Otro ámbito que documenta esta tendencia a la pérdida de la preeminencia individual sería la llamada "reforma hoplita" que suele asociarse con el arranque de la pólis.

14 Cf. Míguez Barciela (2017).

15 Cf. Míguez Barciela (2014). 